\title{
Functional and radiological outcome after closed reduction and percutaneous pinning versus open reduction and internal fixation in displaced supracondylar fractures in children
}

\author{
Amin Kumar Shrestha ${ }^{1}$, Suresh Uprety ${ }^{2}$, Govinda K.C. ${ }^{2}$, Sharma Paudel ${ }^{3}$ \\ ${ }^{1}$ Department of Orthopaedics, Nepal Police Hospital, Kathmandu \\ ${ }^{2}$ Department of Orthopedics, Tribhuvan University Teaching Hospital, Maharajgunj, Kathmandu \\ ${ }^{3}$ Department of Radiology and Imaging, Tribhuvan University Teaching Hospital, Maharajgunj, Kathmandu
}

Correspondence: Dr. Amin Kumar Shrestha

Email: draminshrestha@gmail.com

\begin{abstract}
Introduction: Supracondylar fracture of humerus is very common fracture in pediatric age group. The current trends of management in displaced type are close reduction and per cutaneous pinning (CRPP), if reduction is not satisfactory then open reduction and internal fixation (ORIF) is done. Our study aims to compare the cosmetic, functional and radiological outcome between these two methods.

Methodology:Children with displaced extension type supracondylar fracture of distal humerus presenting to emergency room and orthopedics OPD who could meet the inclusion criteria were taken up for study. Sixty-three such patients (37 CRPP and 26 ORIF) were included in the study. Radiological and functional outcomes were followed up at 8 weeks post-operatively.

Results: Of the 63 patients enrolled, $26(41.3 \%)$ patients had undergone open reduction and internal fixation and $37(58.7 \%)$ had undergone close reduction and percutaneous pinning. The mean age of patients in CRPP and ORIF groups was $7.29 \pm 2.3$ years and $8.11 \pm 2.02$ years respectively. Maximum patients were from age group 7-9 years (46\%). Left side was more commonly injured $(66.7 \% \mathrm{vs}$. $33.3 \%)(\mathrm{P}=0.045)$. According to the Flynn's criteria, cosmetically the outcome did not differ between the two surgical groups $(\mathrm{P}=0.23)$. However, $\mathrm{CRPP}$ proved to have a significantly better functional outcome $(\mathrm{P}=0.000)$. The mean Bauman's angle in CRPP and ORIF groups was $16.89 \pm 5.66$ and $18.88 \pm 4.90$ degrees respectively. However, there is no statistically significant difference between type of fixation and Bauman's angle or Anterior humeral line.
\end{abstract}

Conclusions:Close reduction and percutaneous pinning (CRPP) has better functional and radiological outcome in comparison with open reduction and internal fixation (ORIF) in displaced supracondylar fracture of humerus in children.

Keywords: Supracondylar fracture, Anterior humeral line, Baumann's angle, Flynn's Criteria 


\section{Introduction}

Supracondylar fracture of the humerus is the most common fracture around the elbow in children and represents approximately $3 \%$ of all fractures in children. Supracondylar humerus fractures are caused by fall onto an out stretched hand and divided into two types, extension type and flexion type. About $96 \%$ of supracondylar fractures are extension type and are further classified as described by Gartland according to the degree of displacement of the distal fragment. The age range in which most supracondylar fractures occur is between five and seven years old. ${ }^{1}$ Supracondylar fractures of the distal humerus often instills a sense of apprehension in the treating surgeon with regards to the potential complications like neurovascular injuries, Volksman's ischemia, malunion and cubitus varus. ${ }^{2}$ In western set up two third of the hospital admission of children due to elbow injuries are because of supracondylar fracture. ${ }^{3}$ In our set up, $22.2 \%$ patients with supracondyalr fractures required

hospitalization. ${ }^{4}$ Currently, the preferred approach on the treatment of displaced pediatric supracondylar fractures is, closed reduction and percutaneous pin fixation; if not possible, then internal fixation following an open reduction. ${ }^{5}$ Advantages of percutaneous pinning include rapidity and absence of periosteal separation and dissection, which result in a minimal risk of infection. Disadvantages are the higher risk of iatrogenic nerve injury and the radiation hazard. The open technique allows fracture reduction under direct visual guidance, which limits the risk of ulnar nerve injury, but is associated with soft tissue injury, higher risks of infection, and may result in unsightly or painful scars. ${ }^{6}$

In developing countries like Nepal, it is not possible to manage in all places by close reduction and percutaneous k- wire fixation for all displaced supracondyalr fractures because of economic constrains, lack of expertise and instruments like image intensifier. The current trend in our hospital for the treatment of displaced pediatric supracondylar fractures is, closed reduction and percutaneous pinning with two parallel or divergent lateral pins; when the closed reduction is not satisfactory with two attempts, open reduction internal fixation by posterior triceps splitting approach with two crossed K-wires.The purpose of this study is to bring forward the comparison of the results between open reduction and internal fixation via posterior triceps splitting approach group and close reduction and percutaneous pinning group in our set up which could guide us in deciding whether to continue with present trend or make an amendment.

\section{Methods}

The non randomized, prospective and analytical study included 63 children (37 CRPP and 26 ORIF) aged 414 years with displaced extension type supracondylar fracture of distal humerus presenting to emergency room and orthopedics OPD of TU Teaching Hospital (TUTH), Kathmandu from April 2013 to September 2014 after ethical clearance and written consent. Radiological and functional outcomes were followed up at 8 weeks postoperatively.

Inclusion Criteria were, all the children with 4-14 years of age with displaced extension type supracondylar fracture of humerus presenting to Department of Orthopedics or Emergency at IOM,TUTH during the study period. Gartland Type -I supracondylar fracture, associated injury in the same limb, supracondylar fracture ( Flexion type) and open fracture were excluded.

\section{Results}

Of the 63 patients enrolled, $26(41.3 \%)$ patients had undergone open reduction and internal fixation and 37 (58.7\%) had undergone close reduction and percutaneous pinning. The mean age of patients in CRPP and ORIF groups was $7.29 \pm 2.3$ years and $8.11 \pm 2.02$ years respectively. Maximum patients were from age group 7-9 years (46\%). Left side was more commonly injured $(66.7 \%$ vs. $33.3 \%)$ $(P=0.045)$. According to the Flynn's criteria, cosmetically the outcome did not differ between the two surgical groups $(\mathrm{P}=0.23)$. However, CRPP proved to have a significantly better functional outcome ( $\mathrm{P}=0.000)$. The mean Bauman's angle in CRPP and ORIF groups was $16.89 \pm 5.66$ and $18.88 \pm 4.90$ degrees respectively. However, there is no statistically significant difference between type of fixation and Bauman's angle or Anterior humeral line.

The mean age of patients in CRPP and ORIF groups was $7.29 \pm 2.3$ years and $8.11 \pm 2.02$ years respectively. The patient's age was similar in both the groups and the distribution in both groups was statistically not significant. (Table 1) 
Table 1: Mean Age Vs Type of Fixation

\begin{tabular}{|c|c|c|c|c|c|}
\hline Type of Fixation & $\begin{array}{l}\text { Frequency } \\
\qquad(\%)\end{array}$ & Minimum Age & Maximum Age & $\begin{array}{c}\text { Mean Age } \\
\text { (S.D.) }\end{array}$ & $\begin{array}{l}\text { Independent t-test } \\
\text { p-value }\end{array}$ \\
\hline CRPP & $\begin{array}{l}37 \\
(58.7 \%)\end{array}$ & $4 \mathrm{yrs}$ & $12 \mathrm{yrs}$ & $\begin{array}{l}7.29 \\
(2.30)\end{array}$ & 0.142 \\
\hline ORIF & $\begin{array}{l}26 \\
(41.3 \%)\end{array}$ & 5 yrs & $12 \mathrm{yrs}$ & $\begin{array}{c}8.11 \\
(2.02)\end{array}$ & \\
\hline
\end{tabular}

Left side was more commonly injured than right side (66.7\% vs. 33.3\%). This is statistically significant (P value 0.045$)$. In both CRPP group and ORIF group, left side involvement was predominant.

All the type II S/C \# in our study (12 patients) underwent CRPP which is statistically significant. In patients with type III $\mathrm{S} / \mathrm{C}$ \# 25 out of 51 (39.7\%) underwent CRPP and 26 out of 51 (41.3\%) underwent ORIF. (Table 2)

Table 2:Gartland's Fracture Type versus Type of Fixation

\begin{tabular}{|c|c|c|c|}
\hline \multirow{2}{*}{ Fracture Type } & \multicolumn{2}{|c|}{ Fixation } & \multirow[b]{2}{*}{ Total } \\
\hline & CRPP & ORIF & \\
\hline Gartland's type II & 12 & 0 & 12 \\
\hline \multirow[b]{2}{*}{ Gartland's type III } & $(19.0 \%)$ & $(0.0 \%)$ & $(19.0 \%)$ \\
\hline & 25 & 26 & 51 \\
\hline \multirow{3}{*}{ Total } & $(39.7 \%)$ & $(41.3 \%)$ & $(81.0 \%)$ \\
\hline & 37 & 26 & 63 \\
\hline & $(58.7 \%)$ & $(41.3 \%)$ & $(100.0 \%)$ \\
\hline
\end{tabular}

$(\mathrm{P}=0.001)$

Table 3: Outcome According To Flynn's Criteria Vs Type of Fixation

\begin{tabular}{|c|c|c|c|c|}
\hline $\begin{array}{l}\text { Flynn Criteria } \\
\text { (Loss of Carrying Angle) }\end{array}$ & $\begin{array}{l}\text { Fixation } \\
\text { CRPP }\end{array}$ & ORIF & Total & P-value \\
\hline Excellent & 31 & 20 & 51 & 0.23 \\
\hline Good & 6 & 4 & 10 & \\
\hline Fair & 0 & 2 & 2 & \\
\hline Total & 37 & 26 & 63 & \\
\hline
\end{tabular}

Overall outcome was Excellent in 51 out of total 63 patients (68.2\%). 31 out of 37 patients (83.7\%) in CRPP group had excellent outcome where as 20 out of 26 patients $(76.9 \%)$ in ORIF group had excellent result which was statistically not significant. (Table 3) 
Table 4: Outcome According To Flynn's Criteria and Type of Fixation

\begin{tabular}{|c|c|c|c|c|c|}
\hline $\begin{array}{l}\text { Flynn's Criteria } \\
\text { ( Loss of ROM) }\end{array}$ & $\begin{array}{l}\text { Fixation } \\
\text { CRPP }\end{array}$ & ORIF & Total & $\begin{array}{l}\text { Pearson's Co-relation } \\
\text { Coefficient (R) (p-value) }\end{array}$ & $\begin{array}{l}\text { Chi-square } \\
\text { test p-value }\end{array}$ \\
\hline Excellent & 9 & 0 & 9 & $\begin{array}{l}0.705 \\
(0.000)\end{array}$ & 0.000 \\
\hline Good & 16 & 0 & 16 & & \\
\hline Fair & 8 & 7 & 15 & & \\
\hline Poor & 4 & 19 & 23 & & \\
\hline Total & 37 & 26 & 63 & & \\
\hline
\end{tabular}

Nine out of nine patients (100\%) having excellent functional outcome were from CRPP group where as 19 out of 23 patients $(82.6 \%)$ having poor functional outcome were from ORIF group, which was highly statistically significant. (Table 4)

The mean Bauman's angle in CRPP and ORIF groups was 16.89 \pm 5.66 and $18.88 \pm 4.90$ degrees respectively. However, there is no statistically significant difference between type of fixation and Bauman's angle. (Table 5,6)

Table 5: Bauman's Angle and Type of Fixation

\begin{tabular}{|c|c|c|c|}
\hline Fixation & $\mathrm{N}$ & Bauman's Angle Mean (SD) & Independent t-test p-value \\
\hline CRPP & 37 & $16.89(5.66)$ & 0.142 \\
\hline ORIF & 26 & $15.9 \quad(4.73)$ & \\
\hline
\end{tabular}

Table 6: Anterior Humeral Line vs. Type of Fixation

\begin{tabular}{|c|c|c|c|c|}
\hline \multirow{2}{*}{ AHL } & \multicolumn{2}{|c|}{ Fixation } & \multirow{2}{*}{ Total } & \multirow{2}{*}{$\begin{array}{l}\text { Chi-square } \\
\text { test p-value }\end{array}$} \\
\hline & CRPP & ORIF & & \\
\hline A3 & 25 & 16 & 41 & 0.276 \\
\hline M3 & 6 & 2 & 8 & \\
\hline P3 & 1 & 0 & 1 & \\
\hline NT & 5 & 8 & 13 & \\
\hline Total & 37 & 26 & 63 & \\
\hline
\end{tabular}

There is no significant difference between type of fixation and AHL. 


\section{Discussion}

The aim of the treatment of pediatric supracondylar humerus fractures is to achieve an upper extremity with acceptable cosmetic and functional traits, showing a normal range of motion. ${ }^{3}$ The current trend in our hospital for the treatment of displaced pediatric supracondylar fractures is, closed reduction and percutaneous pinning with two parallel or divergent lateral pins; when the closed reduction is not satisfactory with two attempts, open reduction internal fixation by posterior triceps splitting approach with two crossed K-wires. The purpose of this study was to compare the outcome between these two groups.

\section{Radiological Outcome}

In our study, the mean Bauman's angle in CRPP and ORIF group was $16.89 \pm 5.66$ and $18.88 \pm 4.9$ degrees respectively. There is no statistically significant $(\mathrm{P}=0.142)$ difference between type of fixation and Bauman's angle.

In the similar study done in French children by Yokrech J.B. et al. ${ }^{6}$, the mean Bauman's angle was 16.9 and 15.24 in CRPP and ORIF groups respectively. Thus the Bauman's angle was comparable in both the studies in CRPP groups however the angle was higher in ORIF group.

Anterior humeral line (AHL) is directly related to the anterior and posterior translation and rotation of the distal humeral fragment however, it does not provide any information about capitellum. In present study, AHL of 25 out of $37(67.56 \%)$ patients of CRPP group passed through anterior $3^{\text {rd }}$ of the capitellum, whereas; in 16 out of 26 $(61.53 \%)$ patients of ORIF group, AHL passed through anterior $3^{\text {rd }}$. There is no statistically significant $(\mathrm{P}=0.276)$ difference between type of fixation and AHL.

To the best of our knowledge, there is no similar study found till date in English literature, however, there is one study done in Turkish children by Turhan E et al. ${ }^{7}$ in 2008, to compare the radiological outcomes of close reduction percutaneous pinning with open reduction in displaced supracondylar fractures in children. Seventy-six patients (54 boys, 22 girls, mean age 7.6, range 2-12) were treated by closed reduction and cross percutaneous pinning while 68 (49 boys, 19 girls, mean age 7.3, range 2-13) were treated by open reduction. The reduction quality of the open and closed groups was compared on immediate post-operative lateral radiographs by measuring of lateral humerocapitellar angle, anterior humeral line and anterior coronoid line criteria. They concluded that there was no significant difference between closed and open reductions of pediatric displaced supracondylar fractures with regard to the radiological criteria of reduction quality in sagittal plane. $^{7}$

In present study, image intensifier was used in CRPP group for fracture reduction while fracture was reduced under direct vision in ORIF group. Fixation with k-wires were done only after the achievement of acceptable reduction, and measurement of Baumann's angle and anterior humeral line is totally $\mathrm{x}$-ray view dependent so there might be chance of some measurement error so, this could be the reason behind statistically insignificant result of Bauman's angle and AHL compared with the type of fixation .

\section{Cosmetic and Functional Outcome}

In our study, cosmetic outcome (loss of carrying angle in degrees) and functional outcome (loss of ROM in degrees) in both the CRPP and ORIF groups was compared using Flynn's criteria. Analyzing the cosmetic outcome in both the groups, 31 patients $(83.7 \%)$ in CRPP group had excellent outcome while all the remaining 6 patients $(16.3 \%)$ had good outcome. However, 20 (76.92\%), 4 (15.38\%) and 2 (7.69\%) patients in ORIF group had excellent, good and fair outcome respectively. None of the patients in both the groups had poor cosmetic outcome in our study. This result was statistically not significant $(\mathrm{P}=0.23)$. Similarly, analyzing the functional outcome in both the groups, 9 $(24.3 \%), 16(43.2 \%), 8(21.6 \%)$ and $4(10.8 \%)$ patients in CRPP group had excellent, good, fair and poor outcome respectively. However in ORIF group none of the patients had excellent or good functional outcome. Seven (26.9\%) patients had fair functional outcome and 19 (73.1\%) had poor functional outcome. This result was highly statistically significant $(\mathrm{P}=0.000)$.

Cosmetically the outcome did not differ between the two surgical groups. However, closed reduction and percutaneous pinning proved to have a significantly better functional outcome. This poor functional outcome in ORIF group might be because of more soft tissue dissection, presence of surgical scar in the posterior aspect of elbow joint in ORIF group and early final follow up assessment (8 weeks post operatively). 
In a study done in French children by Yaokreh J.B.et al ${ }^{6}, 51.5 \%$ patients in CRPP group had excellent outcome while 9.1\% patients had poor outcome according to Flynn's criteria. Similarly, in ORIF group, 56\% had excellent outcome and $8 \%$ had poor outcome. This study showed comparable functional and cosmetic outcomes using Flynn's criteria with both the treatment modalities for supracondylar fracture.

\section{Table 8: Comparison of cosmetic outcome in different studies based on Flynn's criteria}

\begin{tabular}{|c|c|c|c|c|c|c|}
\hline $\begin{array}{l}\text { Cosmetic } \\
\text { outcome } \\
\text { (Loss Of } \\
\text { Carrying } \\
\text { Angle) }\end{array}$ & Our study & $\begin{array}{l}\text { CRPP } \\
\text { Aktekin et } \\
\text { l }^{8}\end{array}$ & Ozkoc et al ${ }^{9}$ & Our study & $\begin{array}{l}\text { ORIF } \\
\text { Aktekin et } \\
\text { al }^{8}\end{array}$ & Ozkoc et al $\mathbf{l}^{9}$ \\
\hline Excellent & $31(83.7 \%)$ & $24(75 \%)$ & $40(73 \%)$ & $20(76.92 \%)$ & $14(61 \%)$ & $31(70 \%)$ \\
\hline Good & $6(16.3 \%)$ & $5(16 \%)$ & $6(11 \%)$ & $4(15.38 \%)$ & $3(13 \%)$ & $6(14 \%)$ \\
\hline Fair & $0(0 \%)$ & $2(6 \%)$ & $6(11 \%)$ & $2(7.69 \%)$ & $2(9 \%)$ & $5(11 \%)$ \\
\hline Poor & $0(0 \%)$ & $1(3 \%)$ & $3(5 \%)$ & $0(0 \%)$ & $4(17 \%)$ & $2(5 \%)$ \\
\hline Total & $37(100 \%)$ & $32(100 \%)$ & $55(100 \%)$ & $26(100 \%)$ & $23(100 \%)$ & $44(100 \%)$ \\
\hline
\end{tabular}

Both the studies done by Aktekin et $\mathrm{al}^{8}$ and Ozkoc et $\mathrm{al}^{9}$ showed the comparable cosmetic outcome in both the CRPP and ORIF groups, which is similar to our study.

Table 9: Comparison of functional outcome in different studies based on Flynn's criteria

\begin{tabular}{|c|c|c|c|c|c|c|}
\hline $\begin{array}{l}\text { Functional } \\
\text { outcome } \\
\text { (Loss Of } \\
\text { ROM) }\end{array}$ & Our Study & $\begin{array}{l}\text { CRPP } \\
\text { Aktekin et } \\
\text { al }^{8}\end{array}$ & Ozkoc et al9 & Our study & $\begin{array}{l}\text { ORIF } \\
\text { Aktekin et } \\
\text { al }^{8}\end{array}$ & Ozkoc et al ${ }^{9}$ \\
\hline Excellent & $9(24.3 \%)$ & $22(69 \%)$ & $39(71 \%)$ & $0(0 \%)$ & $8(35 \%)$ & $21(48 \%)$ \\
\hline Good & $16(43.2 \%)$ & $7(22 \%)$ & $5(9 \%)$ & $0(0 \%)$ & $4(17 \%)$ & $6(14 \%)$ \\
\hline Fair & $8(21.6 \%)$ & $1(3 \%)$ & $7(13 \%)$ & $7(26.9 \%)$ & $5(22 \%)$ & $4(11 \%)$ \\
\hline Poor & $4(10.8 \%)$ & $2(6 \%)$ & $4(7 \%)$ & $19(73.1 \%)$ & $6(26 \%)$ & $13(5 \%)$ \\
\hline Total & $37(100 \%)$ & $32(100 \%)$ & $55(100 \%)$ & $26(100 \%)$ & $23(100 \%)$ & $44(100 \%)$ \\
\hline
\end{tabular}


Both the studies done by Aktekin et $\mathrm{al}^{8}$ and Ozkoc et $\mathrm{al}^{9}$ showed the CRPP has the significant better functional outcome in comparison with ORIF groups, which is similar to our study

\section{Conclusion}

Close reduction and percutaneous pinning (CRPP) has better functional and radiological outcome in comparison with open reduction and internal fixation (ORIF) in displaced supracondylar fracture of humerus in children. This is a nonrandomized study with small sample size and measurement of Baumann's angle and anterior humeral line is totally x-ray view dependent, so there might be chances of measurement error. Our study evaluates the final functional outcome in 8 weeks post operatively. Probably a better functional outcome would have been depicted if we had been able to follow up for a prolong duration because there is evidence that improvement continues even up to one year.

\section{Reference}

1. Hakim A, Khan NU, Gul T. Closed reduction and percutaneos pinning with crossed $\mathrm{K}$-wires in type III supracondylar fractures in children. Pak J Surg. 2010;26(1):10-12

2. Cheng JC, Lam TP, Maffulli N. Epidemiological features of supracondylar fractures of the humerus in Chinese children. J Pediatr Orthop B. 2001;10(1):637.

3. Walloe A, Egund N, Eikelund L. Supracondylar fracture of the humerus in children: review of closed and open reduction leading to a proposal for treatment. Injury. 1985;16(5):2969.

4. Mahara DP, Pradhan CB. Supracondylar fractures in children. Journal of institute of Medicine. 1993.

5. Wilkins KE. 1991. In: Wilkins KE, King RE, editors. Fractures in Children1991.

6. Yaokreh JB, Gicquel P, Schneider L, Stanchina C, Karger C, Saliba E, et al. Compared outcomes after percutaneous pinning versus open reduction in paediatric supracondylar elbow fractures. Orthopaedics \& Traumatology: Surgery \& Research.
2012;98(6):645-51.

7. Turhan E, Aksoy C, Ege A, Bayar A, Keser S, Alpaslan M. Sagittal plane analysis of the open and closed methods in children with displaced supracondylar fractures of the humerus (a radiological study). Arch Orthop Trauma Surg. 2008;128(7):739-44.

8. Aktekin $\mathrm{CN}$, Toprak A, Ozturk AM, Altay M, Ozkurt B, Tabak AY. Open reduction via posterior triceps sparing approach in comparison with closed treatment of posteromedial displaced Gartland type III supracondylar humerus fractures. J Pediatr Orthop B. 2008;17(4):171-8.

9. Ozkoc G, Gonc U, Kayaalp A, Teker K, Peker TT. Displaced supracondylar humeral fractures in children: open reduction vs. closed reduction and pinning. Arch Orthop Trauma Surg. 2004;124(8):547-51. 